\section{A) Check for updates}

Cite this: Polym. Chem., 2020, 11 2070

Received 17th November 2019, Accepted 6th February 2020

DOI: 10.1039/c9py01735f

rsc.li/polymers

\title{
Lithium and magnesium polymeric electrolytes prepared using poly(glycidyl ether)-based polymers with short grafted chains $\uparrow$
}

\author{
Marco Viviani, ${ }^{a}$ Niels Laurens Meereboer, ${ }^{a}$ Ni Luh Putu Ananda Saraswati, ${ }^{\text {a,b }}$ \\ Katja Loos (iD ${ }^{a}$ and Giuseppe Portale (iD *a
}

\begin{abstract}
Recently, poly(allyl glycidyl ether) (PAGE) has attracted great interest as a polymer electrolyte for Li-ion transport with conductivity values well above that of the benchmark polyethylene oxide polymer at temperatures below $60^{\circ} \mathrm{C}$. Here, we prepared lithium and magnesium polyelectrolytes by using two novel PAGE-based matrixes containing thioether and sulfone functionalities located in a short side chain inserted by the chemical post-functionalization of PAGE. The synthesized PAGEs, poly(2-(ethyl thio) propyl glycidyl ether) (PEthioPGE) and poly(2-(ethyl sulfone) propyl glycidyl ether) (PEsulfoPGE), were all amorphous at any temperature with $T_{\mathrm{g}}$ between $-80{ }^{\circ} \mathrm{C}$ and $-30{ }^{\circ} \mathrm{C}$. These polymers were used to formulate electrolytes with different $\mathrm{Li}$ and $\mathrm{Mg}$ salts. The impact of the side chain, used salt and temperature on the ionic conductivity was studied in detail. Ionic conductivities as high as $5.1 \times 10^{-4} \mathrm{~S} \mathrm{~cm}^{-1}$ at $90^{\circ} \mathrm{C}$ can be achieved using PAGE-LiTFSI and PEthioPGE-LiTFSI, values comparable to that achieved using PEO-LiTFSI with identical salt loading. When $\mathrm{LiCl}$ is used, PEthioPGE outperforms all other polymers including PEO with the highest conductivity value at $90{ }^{\circ} \mathrm{C}\left(1.1 \times 10^{-5} \mathrm{~S} \mathrm{~cm}^{-1}\right)$. Moreover, the studied complexes with magnesium salts showed promising ionic conductivities, comparable to those achieved using lithium and up to $4.1 \times 10^{-4} \mathrm{~S} \mathrm{~cm}^{-1}$ at $90{ }^{\circ} \mathrm{C}$ for PAGE-Mg(TFSI) 2 . The results presented here highlight the possibility of tuning the structures and the complexation properties of poly(glycidyl ether)-based electrolytes towards both lithium and magnesium ions.
\end{abstract}

\section{Introduction}

Due to climate change and the related need to reduce the dependence on fossil fuels, development of alternative and renewable energy sources has drawn increasing attention. Harvesting renewable energy has several implications related to natural sources, making power generation less controllable and harder to manage in terms of energy distribution. Energy

\footnotetext{
${ }^{a}$ Macromolecular Chemistry and New Polymeric Materials, Zernike Institute for Advanced Materials, University of Groningen, Nijenborgh 4, 9747AG Groningen, The Netherlands.E-mail: g.portale@rug.nl

${ }^{b}$ Inorganic and Physical Chemistry Division, Faculty of Mathematics and Natural Sciences, Bandung Institute of Technology, Jalan Ganesha 10, 40132 Bandung, Indonesia

$\dagger$ Electronic supplementary information (ESI) available: ${ }^{13} \mathrm{C}$ NMR of pure polymers, GPC traces of polymers, FTIR spectra of polymer electrolytes, FTIR comparison of the vibrational frequencies of the TFSI anion in polymer electrolytes and in the LiTFSI salt, DSC curves of polymer electrolytes, TGA of pure polymers, summary of $T_{\mathrm{g}}$ and thermal properties of polymer electrolytes and pristine polymers, typical Nyquist plots of $\mathrm{Mg}(\mathrm{TFSI})_{2}$-PAGE and the equivalent circuit used to fit the data for extracting the bulk resistance and Vogel-Tammann-Fulcher (VTF) plots of polymer electrolytes. See DOI: 10.1039/c9py01735f
}

storage devices play a key role in overcoming these issues and secondary batteries are optimal systems due to their versatility.

While the market for rechargeable batteries is still dominated by lead-acid batteries, the increasing demand for rechargeable portable and automotive devices has raised the production of lithium batteries (LiBs). LiBs are the best candidates for compact and high-performance applications due to their light weight, flexibility and high power density. ${ }^{1,2}$ Lithium is the lightest metal with the highest electrochemical reduction potential $(-3.04 \mathrm{~V}$ vs. SHE), allowing the design of high energy density batteries. ${ }^{3,4}$ Apart from all these benefits, some drawbacks still need to be addressed: shortcuts caused by dendrite formation at the anode/electrolyte interface, reduced efficiency over time due to passivation layer growth at the electrode/electrolyte interface and the safety issues related to the intrinsic reactivity of metallic lithium. ${ }^{3}$ Another critical aspect is the balance between the natural abundance of lithium and the global demand for LiBs which is expected to increase significantly in the coming decades, especially due to automotive electrification. $^{2,5}$ All these concerns related to lithium technology stimulated research on alternative metals to overcome its disadvantages and limitations. 
Among the other mono- and multivalent cations, magnesium seems to be the most promising element due to its potentially higher volumetric specific capacity $\left(3.8 \mathrm{~A} \mathrm{~h} \mathrm{~cm}^{-3}\right.$ vs. $\left.2.0 \mathrm{~A} \mathrm{~h} \mathrm{~cm}^{-3}\right)$. Although it has a lower reduction potential $\left(-2.37 \mathrm{~V} v s\right.$. SHE) and a lower specific capacity $\left(2.2 \mathrm{~A} \mathrm{~h} \mathrm{~g}^{-1} v s\right.$. $3.9 \mathrm{~A} \mathrm{~h} \mathrm{~g}^{-1}$ ) compared to lithium, this alkaline earth metal is the eighth-most abundant element in the Earth's crust and its lower reactivity allows for making metal electrodes without forming dendrites. ${ }^{3,6-8}$ In the case of magnesium batteries (MgBs) the main disadvantage is the passivation of the anode which has a much more detrimental effect than in the LiBs due to the impermeability of the layer to the $\mathrm{Mg}^{2+}$ ions. ${ }^{9}$

While liquid electrolytes represent the benchmarks for both LiBs and MgBs in terms of conductivity, they are unfortunately volatile, flammable and pollutants, leading to safety problems in the manufacture, handling and disposal/recycling of the batteries. Compared to the LiBs, the MgBs have additional challenges regarding the stability of the electrolytes and their performances which make it difficult to adopt the same solutions as those used for the lithium batteries. ${ }^{6,7,10}$ In order to overcome all these complications, several approaches have been attempted spanning from organic gels to inorganic solid electrolytes. ${ }^{6,7,11}$

Among these approaches, polymer electrolytes (PEs) have shown potential for substituting small-molecule liquid electrolytes, allowing the development of safer solvent-free and better performing (metal anode) batteries. ${ }^{4,12}$ However, these benefits are offset by their reduced ionic conductivity, leading to a gap between the theoretical and accessible performances of these devices. ${ }^{13}$ Ever since Fenton et al. ${ }^{14}$ discovered that poly(ethylene oxide) (PEO) can solvate sodium iodide, polyether-based electrolytes have attracted significant interest. The peculiar solvation properties towards lithium and magnesium cations of this class of polymers are the result of the strong interaction between the ions and the oxygen atoms along the polymer chains resulting in a chelate structure which affects the segmental mobility and the transport mechanism of the final complexes. ${ }^{15-20}$ Despite their low $T_{\mathrm{g}}$ values, the residual crystallinity of PEO-based electrolytes is responsible for conductivity drop below their melting point $\left(T<65^{\circ} \mathrm{C}\right)$ essentially limiting the practical use of these PEs. Research on alternative polymers with high conductivity at room temperature has a non-trivial solution. The presence of polar groups, necessary for endowing the polymers good solvation properties towards $\mathrm{Li}$ and $\mathrm{Mg}$ salts, is also responsible for chain stiffening and eventually crystallinity.

Polyethers, polycarbonates, polynitriles, polyesters, polyamines and polyalcohols have been explored as potential polymer electrolytes and a recent comprehensive review has summarized the past research results for lithium electrolytes. ${ }^{11}$ Polymer magnesium electrolytes were firstly designed based on the lithium approach. In this perspective, poly(ether) $\mathrm{s}^{17,21,22}$ and poly(vinyl alcohol) $\mathrm{s}^{23}$ and their derivatives have been attempted, but the coordination of magnesium dications with the oxygen atoms is stronger than that of lithium, reducing the overall conductivity of the resulting complexes and increasing the related $T_{\mathrm{g}}{ }^{24-26}$ Despite the fact that segmental mobility is considered to be one of the most important factors for high ionic conductivity, an increasing number of studies have highlighted that $T_{\mathrm{g}}$ is not always a vital parameter $^{27-33}$ and also other possible transport mechanisms can contribute to ion mobility in the matrix..$^{31-35}$ In the Salt in Polymer Electrolyte (SIPE) and dilute regimes, the interplay between chain polarity and stiffness is relevant, controlling the solvation mechanisms of the salts and their mobility through the polymer matrices. ${ }^{29,30,36}$

A class of poly(allyl glycidyl)ethers (PAGEs) proposed by Barteau et al. ${ }^{28}$ offered the opportunity to investigate the effect of several structural parameters on the resulting conductivity of the lithium-complexes. Interestingly, the conductivity did not scale monotonically with the $T_{\mathrm{g}}$ of the polymers suggesting additional contributions playing a major role in the ion mobility. Follow-up studies reported by Wheatle et al. ${ }^{29,30}$ confirmed the relevance of the polymer backbone polarity by comparing computational and experimental results obtained for different structures $^{29}$ and by claiming the existence of an optimal compromise between ion solvation and segmental mobility that must be taken into account in designing novel PEs. ${ }^{30}$ Using different heteroatoms than oxygen in the polymer structure is a straightforward method to modify both chain mobility and polarity. Specifically, the presence of sulfur heteroatoms in combination with oxygen has been proved to give encouraging results for lithium transport, even though crystallinity is not prevented. ${ }^{27,37}$ Poly alkyl sulfides alone ${ }^{15}$ proved to be unsatisfactory and the reported higher reactivity of the thioether compared to that of the ether linkage limited the studies on these polymers. On the other hand, the co-presence of both elements led to the formation of complexes with improved electrochemical stability with both lithium and magnesium salts. $^{27,38-40}$

Here we present the synthesis, characterization and transport properties of lithium and magnesium polymer electrolytes based on the post-modification of PAGE. The PAGE polymer has already been synthesized by other groups and shows interesting transport properties, surpassing those of PEO polymers at temperatures below $50{ }^{\circ} \mathrm{C} .{ }^{28}$ Considering its low $T_{\mathrm{g}}$ ( $\mathrm{ca}$. $-80{ }^{\circ} \mathrm{C}$ ) and ease of modification due to the dangling allylic functionality, ${ }^{28}$ we chose allyl glycidyl ether (AGE) as the building block for a new class of fully amorphous polymer electrolytes with low $T_{\mathrm{g}}$ and improved solvation capability towards lithium and magnesium salts. Recently, high $\mathrm{Mg}^{2+}$-ion conductivity, $\mathrm{Mg}$ cycling efficiency and anodic stability have been achieved using $\mathrm{MgCl}_{2}$ salts in dialkyl sulfone electrolytes, motivating our endeavours to investigate both $\mathrm{Li}^{+}-$and $\mathrm{Mg}^{2+}$ ion transport in sulfone containing solid polymer electrolytes. $^{41}$ Three different polymers have been synthesized and studied: pristine PAGE, poly(2-(ethylthio) propyl glycidyl ether) (PEthioPGE) and poly(2-(ethyl sulfone) propyl glycidyl ether) (PEsulfoPGE). Different oxidation states of the sulfur atom allowed for the investigation of the effect of polymer polarity on both chain mobility and ionic conductivity. Four different salts, namely lithium trifluoromethylsulfonimide (LiTFSI), 
lithium chloride (LiCl), magnesium trifluoromethylsulfonimide $\left(\mathrm{Mg}(\mathrm{TFSI})_{2}\right)$ and magnesium chloride $\left(\mathrm{MgCl}_{2}\right)$, were tested to assess the potential application of these new complexes as solvent-free electrolytes for both LiBs and MgBs.

\section{Experimental}

\section{Materials and methods}

Calcium hydride (Acros Organics 93\%), potassium metal cubes in mineral oil (Sigma-Aldrich 99.5\%), ethanethiol (Acros Organics 99+\%), 3-chloroperbenzoic acid (MCPBA) (SigmaAldrich $\leq 77 \%$ ), acetic acid glacial (Merck), and methanol (Macron Fine Chemicals $\geq 99.8 \%$ ) were used as received. Naphthalene (Sigma-Aldrich 99\%) was recrystallized from methanol, and dry tetrahydrofuran (THF) was collected from an MBraun SPS5 solvent purification system and used immediately afterwards. Potassium naphthalenide was prepared from potassium metal and recrystallized naphthalene in anhydrous THF by stirring for $24 \mathrm{~h}$ with a glass-coated stirring bar at room temperature under a nitrogen atmosphere. Benzyl alcohol (Merck $\geq 99.0 \%$ ) was dried over calcium hydride and distilled prior to titration with potassium naphthalenide in THF. Allyl glycidyl ether (AGE) (Sigma-Aldrich $\geq 99 \%$ ) was degassed through five freeze-pump-thaw cycles, dried over $n$-butyl magnesium chloride and distilled in a dried Schlenk tube. The purified AGE was used immediately afterwards. 2,2'Azobis(2-methylpropionitrile) (AIBN) (Sigma-Aldrich $\geq 98 \%$ ) was recrystallized twice from methanol prior to use.

\section{Synthesis of poly(allyl glycidyl ether) (PAGE)}

PAGE was synthesized according to a previously reported procedure $^{42}$ with minor modifications. Freshly distilled benzyl alcohol (1.34 mmol, $0.139 \mathrm{~mL}$ ) was titrated with potassium naphthalenide in a pre-dried Schlenk tube under a nitrogen atmosphere. Potassium naphthalenide was added to the alcohol under stirring through a septum with a degassed syringe and needle until a green color was formed in the solution indicating the complete deprotonation of the alcohol. A pre-determined volumetric amount of AGE (202 mmol, $24 \mathrm{~mL}$ ) was charged into the Schlenk tube with a degassed needle. The reaction mixture was allowed to stir at $35{ }^{\circ} \mathrm{C}$ for 24 hours. The polymerization was quenched with a deoxygenated mixture of acetic acid in methanol. The polymerization mixture was diluted with dichloromethane and passed through a short silica plug to remove salts. The volatiles were removed in vacuo. ${ }^{1} \mathrm{H}$ NMR $\left(400 \mathrm{MHz}, \mathrm{CDCl}_{3}\right): \delta=3.42-3.67$ (broad m, 7H, $-\mathrm{CH}_{2}-\mathrm{CH}-\mathrm{O}-,-\mathrm{CH}_{2}-\mathrm{O}-\mathrm{CH}_{2}-$ ), 3.95-4.03 (d, 2H, $\left.-\mathrm{O}-\mathrm{CH}_{2}-\mathrm{CH}=\right), \quad 5.12-5.30\left(\mathrm{dd}, 2 \mathrm{H}, \quad-\mathrm{CH}=\mathrm{CH}_{2}\right), \quad 5.83-5.97$ (broad m, 1H, $\left.-\mathrm{CH}=\mathrm{CH}_{2}\right)$. $\left(M_{\mathrm{n}}: 14500 \mathrm{~g} \mathrm{~mol}^{-1}\right.$, PDI: 1.09).

\section{Synthesis of poly(2-(ethylthio) propyl glycidyl ether) (PEthioPGE)}

A solution of PAGE (0.053 mmol* 6.00 gram), ethanethiol (0.263 mol, $18.9 \mathrm{~mL}$ ), and AIBN (39.4 mmol, 6.47 gram) in anhydrous THF $(80 \mathrm{~mL})$ was prepared in a pre-dried Schlenk tube under a nitrogen atmosphere. The solution was refluxed for 24 hours and then quenched with methanol. The resulting polymer was extensively washed with methanol using a centrifuge $(5 \times, 3 \mathrm{~min}, 4500 \mathrm{rpm}) .{ }^{1} \mathrm{H}$ NMR (400 $\left.\mathrm{MHz}, \mathrm{CDCl}_{3}\right): \delta=$ 1.20-1.30 (broad m, 3H, $-\mathrm{CH}_{3}$ ), 1.78-1.90 (broad m, 2H, $-\mathrm{CH}_{2}-$ $\mathrm{CH}_{2}-\mathrm{CH}_{2}-$ ), 2.48-2.64 (broad m, 4H, $-\mathrm{CH}_{2}-\mathrm{S}-\mathrm{CH}_{2}-$ ), 3.35-3.65 (broad m, 7H, $-\mathrm{CH}_{2}-\mathrm{CH}-\mathrm{O}-,-\mathrm{CH}_{2}-\mathrm{O}-\mathrm{CH}_{2}-$ ).

*Repeating units AGE.

\section{Synthesis of poly(2-(ethyl sulfone) propyl glycidyl ether) (PEsulfoPGE)}

To a solution of PEthioPGE (2.27 mmol, $400 \mathrm{mg}$ ) in THF (6 mL), meta-chloroperbenzoic acid (11.34 mmol, 1.96 grams) was slowly added. The mixture was stirred for 24 hours at room temperature. The reaction mixture was concentrated and precipitated in cold methanol (liquid nitrogen cooled). Methanol was decanted and the polymer was washed with cold methanol extensively. Finally, the polymer was dried in vacuo. ${ }^{1} \mathrm{H}$ NMR (400 MHz, $\left.\mathrm{CDCl}_{3}\right): \delta=1.33-1.42$ (broad m, $3 \mathrm{H},-\mathrm{CH}_{3}$ ), 2.00-2.15 (broad $\mathrm{m}, 2 \mathrm{H},-\mathrm{CH}_{2}-\mathrm{CH}_{2}-\mathrm{CH}_{2}-$ ), 2.96-3.12 (broad m, 4H, $-\mathrm{CH}_{2}-\mathrm{SO}_{2}-\mathrm{CH}_{2}-$ ), 3.42-3.65 (broad m, $\left.7 \mathrm{H},-\mathrm{CH}_{2}-\mathrm{CH}-\mathrm{O}-,-\mathrm{CH}_{2}-\mathrm{O}-\mathrm{CH}_{2}-\right)$.

\section{Polyelectrolyte preparation}

PAGE-like polymer electrolytes (PEs) were prepared in an MBraun nitrogen glove box, with both $\mathrm{H}_{2} \mathrm{O}$ and $\mathrm{O}_{2}$ concentrations less than $0.1 \mathrm{ppm}$. The preparation of the materials was done by mixing the pristine polymer with a calculated amount of salt. The salt concentration is referred here in terms of the molar ratio $(r)$ of the lithium or magnesium atom to the ether oxygen atoms (EO) in the polymer backbone, [Li]/ [EO] and $[\mathrm{Mg}] /[\mathrm{EO}]$. We used $r=0.06$ which corresponds to 16 EO every lithium or magnesium atom, based on the added materials. This ratio was chosen because it is reported to correspond to the peak in the ionic conductivity for the PAGELiTFSI system. ${ }^{28}$ The samples used in this study are denoted using the notation [polymer name]-[salt name] (i.e. PAGELiTFSI). The lithium and magnesium salts were first vacuumdried at $120{ }^{\circ} \mathrm{C}$ overnight to remove traces of water and then dissolved in a certain amount of extra pure anhydrous DMF solution before use. Approximately $0.2 \mathrm{~g}$ of pristine polymers was placed in glass vials and then mixed with the calculated amount of salt/DMF solution. The solutions were first heated at $60{ }^{\circ} \mathrm{C}$ under a $\mathrm{N}_{2}$ flow. The mixtures were then dried in the glove box-antechamber oven for at least 3 days at $70^{\circ} \mathrm{C}$ under vacuum to completely remove the residual solvent and water. The dried samples were then transferred into the glove box and kept there before being characterized.

\section{Characterization}

Nuclear magnetic resonance $\left({ }^{1} \mathrm{H}\right.$ and ${ }^{13} \mathrm{C}$ NMR $)$ spectra were recorded on a $400 \mathrm{MHz}$ Varian (VXR) spectrometer at room temperature using $\mathrm{CDCl}_{3}$ as the solvent $\left({ }^{13} \mathrm{C}\right.$ NMR spectra are reported in Fig. S1-S3†). Gel Permeation Chromatography (GPC) was performed in DMF (containing 0.01 M LiBr) using a Viscotek GPCmax equipped with model 302 TDA detectors and 
two columns (Agilent Technologies-PolarGel-L and M, $8 \mu \mathrm{m}$

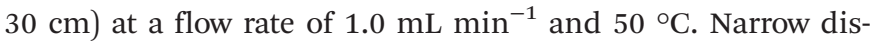
persity PMMA standards (Polymer Laboratories) were used for constructing a universal calibration curve applied for determining the molecular weights of the polymers (GPC traces of the pure polymers are reported in Fig. S4 $\dagger$ ). The Fourier Transform Infrared (FTIR) spectra of the polymers were recorded on a Bruker Vertex 70 spectrophotometer using 32 scans at a nominal resolution of $4 \mathrm{~cm}^{-1}$ using a diamond single reflection attenuated total reflectance (ATR) accessory. Thermogravimetric analysis (TGA) was conducted using a TA Instruments Discovery TGA5500 over the temperature range of $0{ }^{\circ} \mathrm{C}$ to $700{ }^{\circ} \mathrm{C}$ at a $10{ }^{\circ} \mathrm{C} \mathrm{min}^{-1}$ heating rate in air. Differential scanning calorimetry (DSC) was performed using a TA Instruments DSC Q1000 calorimeter. The samples (approximately $5 \mathrm{mg}$ ) were placed in aluminium hermetic pans. DSC scans consisted of two heating and one cooling cycles over the temperature range of $-80^{\circ} \mathrm{C}$ to $100{ }^{\circ} \mathrm{C}$. The first heating rate was $10^{\circ} \mathrm{C} \mathrm{min}^{-1}$, while the cooling and second heating rates were $5^{\circ} \mathrm{C} \mathrm{min}^{-1}$. The $T_{\mathrm{g}}$ values of all samples were determined as the inflection point on the second heating cycle. Ion transport properties were measured via Electrochemical Impedance Spectroscopy (EIS). Polymer electrolyte samples were prepared inside an MBraun nitrogen filled glove box using custom made conductivity cells designed similarly to those reported by Lascaud et al. $^{43}$ Each polymer electrolyte was heated in a closed cell at $80{ }^{\circ} \mathrm{C}$ for about 15 minutes to ensure good contact between the electrodes. After cooling down at room temperature the loaded cell was transferred outside the glove box for impedance measurements. Temperature-dependent AC impedance measurements were performed using the Intermediate Temperature System (ITS/Bio-Logic) connected to a Bio-Logic SP-300 potentiostat. Impedance data were collected every $10{ }^{\circ} \mathrm{C}$ from $90{ }^{\circ} \mathrm{C}$ to $0{ }^{\circ} \mathrm{C}$ with an equilibration time of at least 1 hour at each temperature. The temperature was measured with an accuracy of $\pm 1{ }^{\circ} \mathrm{C}$ by means of a thermocouple inserted in a well dug in the body of the top part of the cell. Impedance measurements were conducted in a throughplane two-electrode mode at an AC voltage of $20 \mathrm{mV}$ and with the frequency ranging from $7 \mathrm{MHz}$ to $1 \mathrm{~Hz}$ with $0 \mathrm{~V} \mathrm{DC}$ bias. Data were acquired and analysed using the EC-Lab software (Bio-Logic). Conductivity values were calculated from complex impedance analysis $\left(|Z|=Z^{\prime}+\mathrm{i} Z^{\prime \prime}\right.$ where $Z^{\prime}$ and $Z^{\prime \prime}$ are the real and the imaginary part of the impedance, respectively). Experimental data were analysed using the equivalent circuit represented in the inset in Fig. $\mathrm{S} 14 \uparrow$ and the bulk resistance $\left(R_{\mathrm{b}}\right)$ obtained from the fitting was used to calculate the sample conductivity $(\sigma)$ according to eqn (1):

$$
\sigma=\frac{k}{R_{\mathrm{b}}}
$$

where $k$ is the cell constant and $R_{\mathrm{b}}$ is the resistance of the sample calculated from the complex impedance data. The cell constant values for all cells were determined at $25{ }^{\circ} \mathrm{C}$ using $0.01 \mathrm{~N}$ potassium chloride standard solution.

\section{Results and discussion}

\section{Polymer matrix synthesis}

The synthetic route towards the polymers used in this study is outlined in Scheme 1. Benzyl alcohol deprotonated by potassium naphthalenide was used as the initiator for the anionic ring-opening polymerization of AGE. To obtain the quantitative conversion of $\mathrm{AGE}$ and to minimize isomerization reactions, the reaction temperature was kept at $35^{\circ} \mathrm{C}$ for 24 hours. The polymerization was terminated by adding acidified methanol. ${ }^{42}$ In this way, narrow disperse PAGE was obtained $(14.5 \mathrm{~kg}$ $\left.\mathrm{mol}^{-1}, Ð=1.05\right)$. The signals corresponding to the protons of PAGE in the ${ }^{1} \mathrm{H}$ NMR spectrum, depicted in Fig. 1a, are in good agreement with literature reports. ${ }^{28,42}$ Subsequently, using a thiol-ene click reaction, the allyl functionality in PAGE was used for introducing side chains containing sulfur heteroatoms. Using ${ }^{1} \mathrm{H}$ NMR spectroscopy, the successful full conversion of the allyl moieties is confirmed by the disappearance of the signals in the regions 5.12-5.30 and 5.83-5.97 ppm corresponding to the $\mathrm{CH}=\mathrm{CH}_{2}$ and $\mathrm{CH}=\mathrm{CH}_{2}$ protons, respectively. The signals appearing at 2.48-2.64 ppm are characteristic of the $-\mathrm{CH}_{2}-\mathrm{S}-\mathrm{CH}_{2}-$ protons surrounding the thioether. The sulfone derivative of this polymer, PEsulfoPGE, was then synthesized by a quantitative oxidation method using $m$-chloroperbenzoic acid. The efficiency of this reaction was demonstrated by the complete downfield shift of the $-\mathrm{CH}_{2}-\mathrm{S}-\mathrm{CH}_{2}-$ protons to 2.96-3.12 ppm caused by an increased shielding of the sulfone groups. In addition, infrared spectroscopy further confirmed the formation of PEsulfoPGE, showing the characteristic sulfone stretching vibration at 1100 and $1300 \mathrm{~cm}^{-1}$ and sulfone bending vibration of $\mathrm{C}-\mathrm{S}$ at around $800-750 \mathrm{~cm}^{-1}$ (Fig. 1b). ${ }^{44}$
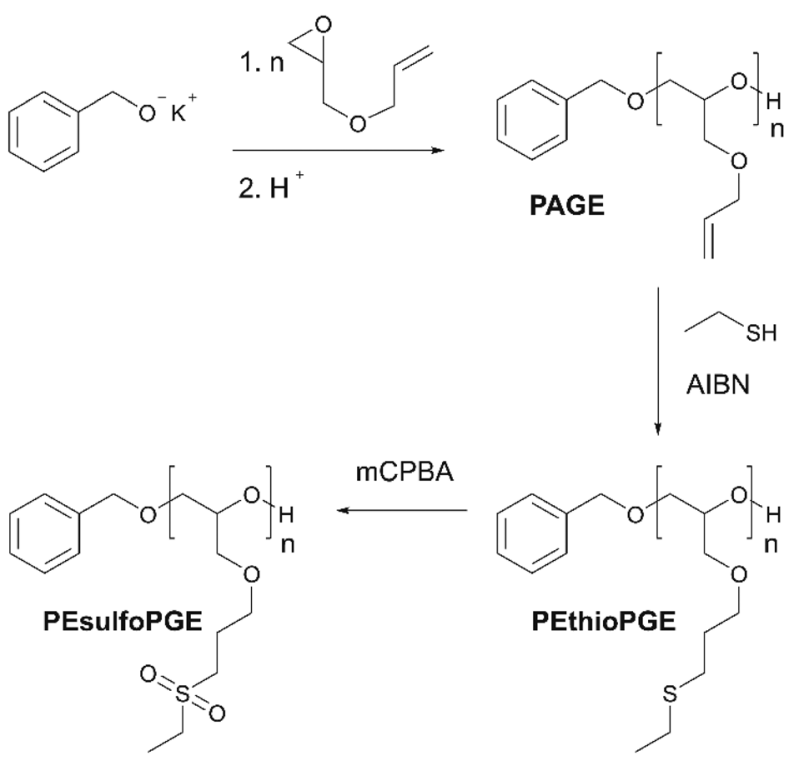

Scheme 1 Synthetic route towards poly(allyl glycidyl ether) (PAGE), poly(2-(ethyl thio) propyl glycidyl ether)(PEthioPGE) and poly(2-(ethyl sulfone) propyl glycidyl ether) (PEsulfoPGE). 
a)

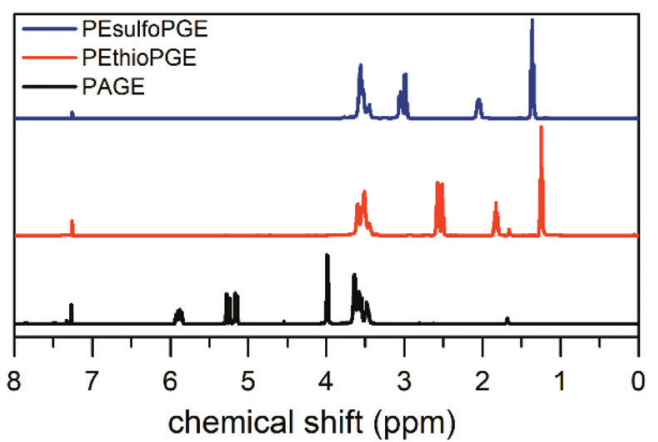

b)



Fig. 1 (a) ${ }^{1} \mathrm{H}$ NMR spectra of PAGE, PEthioPGE and PEsulfoPGE. (b) FTIR spectra of the three different polymers. The stars indicate the positions of the characteristic peaks related to the functional groups: 917 and $995 \mathrm{~cm}^{-1}$ bending of monosubstituted alkenes for PAGE, $1270 \mathrm{~cm}^{-1}-\mathrm{CH}_{2}-$ wagging of aliphatic thioether for PEthioPGE, $1270-1300 \mathrm{~cm}^{-1}-\mathrm{SO}_{2}$-asymmetric stretching vibration of PEsulfoPGE, with marks on the peculiar vibrations of the respective functional groups.

\section{Polymer electrolyte preparation and characterization}

Polymer electrolytes (PEs) were prepared by adding lithium and magnesium salts to the polymers. In addition to the conventional TFSI salts (LiTFSI and $\mathrm{Mg}(\mathrm{TFSI})_{2}$ ), due to the recently reported high dielectric constants of these kinds of polymers ${ }^{29}$ and the presence of the sulfur heteroatoms located on the side chains, we have also decided to investigate complexes with $\mathrm{LiCl}$ and $\mathrm{MgCl}_{2}$. The PEs were prepared by dissolving LiTFSI, $\mathrm{LiCl}, \mathrm{Mg}(\mathrm{TFSI})_{2}$ and $\mathrm{MgCl}_{2}$ in the three different polymers inside a nitrogen-filled glove box. This precaution is needed to avoid moisture absorption by the electrolyte which could affect ionic conductivity measurements. The molar ratio of the lithium or magnesium ions to the oxygen atoms in the repeating unit of the host polymer is crucial for the overall electrolyte conductivity. In this research, the molar ratio, $[\mathrm{Li}] /[\mathrm{EO}]$ or $[\mathrm{Mg}] /[\mathrm{EO}]$, was kept fixed at 0.06 , which is considered to be optimal. $^{26,28,29,45}$ This value means that there is one lithium or magnesium ion every sixteen ether oxygen atoms of the polymer. All salts showed good solubilization inside the polymer matrix except chlorides which were partially insoluble at room temperature, but were readily soluble as soon as the temperature was increased.

The incorporation of the $\mathrm{Li}$ and $\mathrm{Mg}$ salts into the polymer structure was studied by FTIR. Due to the hygroscopic nature of the salts and due to the instrumental limitations to perform the measurements under an inert atmosphere, some complexes presented peaks of water (around 3400 and $1600 \mathrm{~cm}^{-1}$ ) that has been adsorbed only during the short time of the measurements (ESI Fig. S6-S9†). It is generally accepted that when forming a polymer electrolyte, the cations are solvated by coordination to oxygen atoms in the host polymer backbone. ${ }^{46}$ FTIR spectra presented in Fig. 2 clearly show the miscibility of lithium and magnesium ions in the polymers through the change in peaks belonging to the ethereal $\mathrm{CH}_{2}-\mathrm{O}-\mathrm{CH}_{2}$ stretching around $1120 \mathrm{~cm}^{-1}$. In the case of LiTFSI and $\mathrm{Mg}$
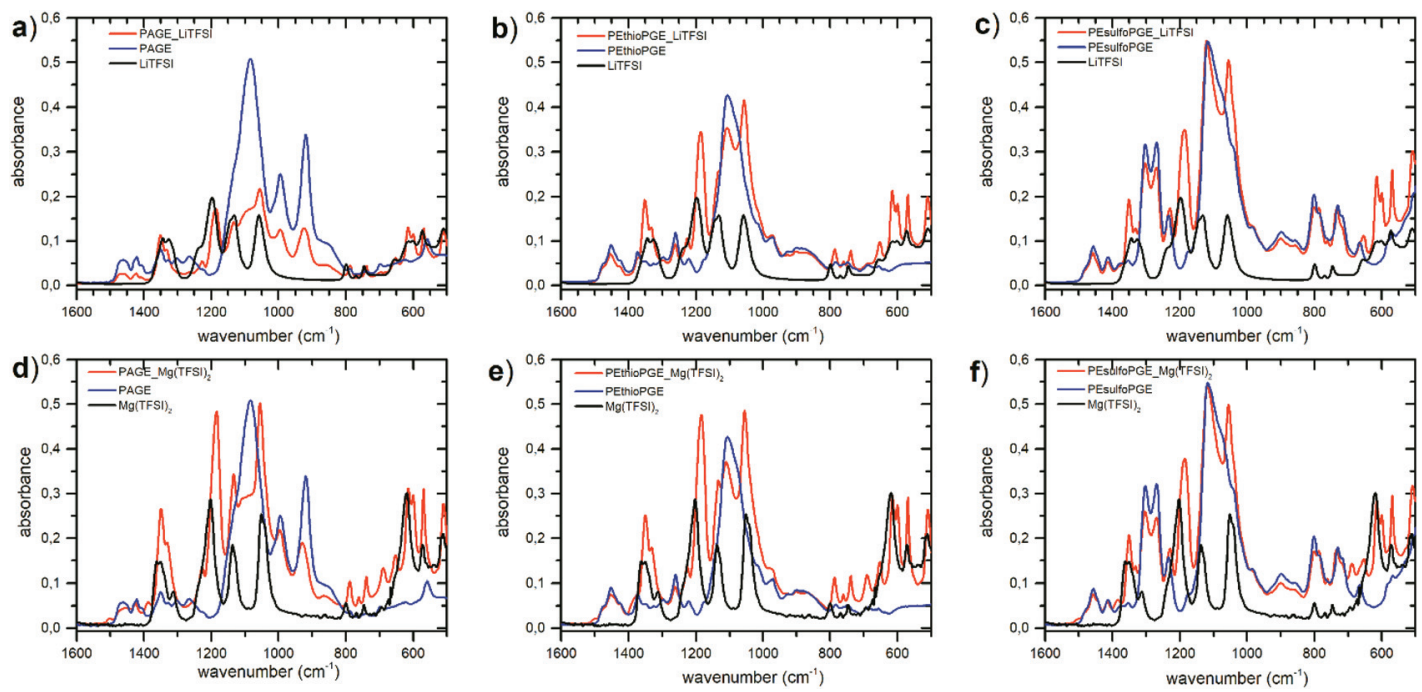

Fig. 2 FTIR spectra of the neat salt, neat polymer and electrolyte complex for (a) PAGE-LiTFSI, (b) PEthioPGE-LiTFSI, (c) PEsulfoPGE-LiTFSI, (d) PAGE-Mg(TFSI)2, (e) PEthioPGE-Mg(TFSI) 2 and (f) PEsulfoPGE-Mg(TFSI) . $^{2}$ 
$(\mathrm{TFSI})_{2}$ salts, the anion absorption peaks also demonstrate the TFSI dissociation in all polymers. In particular, the vibrational frequencies of the anion in pure salts that appear at wavenumbers 800,770 and $746 \mathrm{~cm}^{-1}$ shift to 787,760 and $739 \mathrm{~cm}^{-1}$ in the polymer electrolytes, respectively (ESI Fig. S10†). The shifts of the peaks at 1197,1140 and $1060 \mathrm{~cm}^{-1}$ to lower wavenumbers together with the change in the multiplicity of the peak at $1084 \mathrm{~cm}^{-1}$ are also correlated to the dissociation of the salt in the polymer matrix. These observations are in agreement with what was previously reported by other authors. ${ }^{27,28,47,48}$ In addition, the TFSI bands at around $600 \mathrm{~cm}^{-1}, 614 \mathrm{~cm}^{-1}$ and $656 \mathrm{~cm}^{-1}$ are representative of the convoluted $\delta$ (SNS) vibrations of the transoid and cisoid forms, respectively, which are visible only in a fully dissociated scenario, where a conformational equilibrium is possible. ${ }^{49}$ In contrast, for the salt form, only the peak at $618 \mathrm{~cm}^{-1}$ is visible.

As expected at this concentration, ${ }^{50}$ neither magnesium ions nor lithium ions form ion pairs in any complex. This is represented by a single peak at $740 \mathrm{~cm}^{-1}$ for magnesium ${ }^{50}$ and at $652 \mathrm{~cm}^{-1}$ for lithium. ${ }^{51,52}$ From the IR spectra, it appears quite clear that good solvation of the metal TFSI salts occurs in all matrixes.

For the chloride complexes, it is not possible to rely on the TFSI anion shifts and other characteristics peaks must be taken into account. In these cases, we can refer to the peaks at around $1390 \mathrm{~cm}^{-1}$, characteristic alteration in the wagging frequency of $\mathrm{CH}_{2}-\mathrm{O}$ that depends on the type of polymer-salt combination, and at around $690 \mathrm{~cm}^{-1}$, representing a particular interaction of magnesium with the polymer chain.

The PAGE-LiCl complex did not show any visible shifts or changes in the characteristic IR spectra of pristine PAGE, but both PEthioPGE and PEsulfoPGE show evidence of interactions with the salt (Fig. S5†). PEthioPGE shows some additional bands between $615 \mathrm{~cm}^{-1}$ and $500 \mathrm{~cm}^{-1}$. The increase of the intensity of the peak at around $1354 \mathrm{~cm}^{-1}$ and the absence of a water signal in the rest of the spectra suggest an interaction of the chain with the lithium salt. In the case of PEsulfoPGE, the splitting of the peak at $666 \mathrm{~cm}^{1}$ together with the peak at $1389 \mathrm{~cm}^{-1}$ is in good agreement with the partial dissolution of LiCl due to chain complexation. Finally, for the $\mathrm{MgCl}_{2}$ complexes, PEthioPGE shows no changes in the spectra with the salt, while PAGE only shows a slight increase in the intensity of the peak at around $1390 \mathrm{~cm}^{-1}$ and a shift of the peak at $690 \mathrm{~cm}^{-1}$ as previously observed in the case of $\mathrm{Mg}$ $(\mathrm{TFSI})_{2}$. Conversely, PEsulfoPGE shows signs of a stronger interaction with $\mathrm{MgCl}_{2}$ due to the appearance of a new peak at $690 \mathrm{~cm}^{-1}$ and the inversion of the intensity of the two peaks at 1380 and $1350 \mathrm{~cm}^{-1}$ (Fig. S5†). Our observation is in agreement with previous studies on both lithium and magnesium demonstrating that sulfone oxygen atoms exhibit an increased stronger interaction with the metal cations when compared to ether oxygens. ${ }^{39,53}$

However, despite the observed interaction found via FTIR, in general, both $\mathrm{LiCl}$ and $\mathrm{MgCl}_{2}$ solubility in the polymers is lower than the TFSI salts, and this is also confirmed by the low conductivity values observed for the chloride complexes (vide infra). Ion transport in a polymeric matrix is possible due to two main mechanisms. The first is the ion migration by hopping from one chain to another, predominantly in the amorphous phase. The second is the whole chain diffusion together with the complexed ions. ${ }^{18,54,55}$ A good segmental mobility of the chain is thus crucial to obtain high conductivity values, and hence fully amorphous polymers with low $T_{g}$ perform better than crystalline or glassy polymers. Therefore, we have conducted DSC analysis to determine $T_{\mathrm{g}}$ and any possible traces of crystallinity (ESI Fig. S11, S12 and Table S1†). The three neat polymers do not present any crystallization peak and their $T_{\mathrm{g}}$ values are well below room temperature ranging from -78 to $-37{ }^{\circ} \mathrm{C}$. While PEthioPGE presents a $T_{\mathrm{g}}$ value very similar to PAGE, the $T_{\mathrm{g}}$ value of PEsulfoPGE is about $40{ }^{\circ} \mathrm{C}$ higher, as a result of the increased polarity of the sulfone containing side chains.

The higher oxidation state of the sulfur atoms induces a stronger dipolar association of the chains and a reduction of the segmental mobility with a consequent increase in the $T_{\mathrm{g}}$ value. Such a trend was also observed by Sarapas et al. ${ }^{27}$ for polymers with different architectures but with the same functional groups along the chain.

The addition of LiTFSI and $\mathrm{Mg}(\mathrm{TFSI})_{2}$ salts to the polymers further increases the $T_{\mathrm{g}}$ of the polyelectrolyte complex as a consequence of ion solvation. It is generally accepted that in polyether systems the cations are solvated by coordination to the oxygen atoms in the host polymer backbone, leading to an increase in the chain stiffness. ${ }^{46}$ This explanation is also supported by the shifts of the FTIR peaks as mentioned above. Interestingly, while the addition of LiCl does not cause a shift in the glass transition for any polymer, the addition of $\mathrm{MgCl}_{2}$ shows a clear $T_{\mathrm{g}}$ increase only for the PEsulfoPGE- $\mathrm{MgCl}_{2}$ complex. This is an indication that the PEsulfoPGE polymer is able to efficiently solubilize $\mathrm{MgCl}_{2}$ via the sulfone groups. The comparison of the $T_{\mathrm{g}}$ values of the chloride-complexes with their related FTIR traces corroborates that the weak interactions shown by PAGE and PEthioPGE have no effect on the mobility of the chains. The chloride salts are thus only partially soluble in the host matrix and only the PEsulfoPGE$\mathrm{MgCl}_{2}$ complex shows signs of high solvation.

The thermal stability of both the polymers and the complexes was studied by thermogravimetric analysis (TGA). TGA thermograms showed good thermal stability for all three homopolymers up to $350{ }^{\circ} \mathrm{C}$ (ESI Fig. S13 and Table S2†). According to this result, all three polymers will be thermally stable in the temperature range of polymer electrolyte battery applications.

\section{Ion transport properties}

The transport properties of the prepared $\mathrm{Li}$ and $\mathrm{Mg}$ polymer complexes were measured using electrochemical impedance spectroscopy (EIS). Two typical Nyquist plots of the PAGE-Mg $(\mathrm{TFSI})_{2}$ complex at two different temperatures are reported in Fig. S14. $\dagger$ The conductivity can be calculated using the bulk resistance extracted from the high-frequency semicircle intercept determined according to the fitting curve using an equivalent 
$\mathrm{T}\left({ }^{\circ} \mathrm{C}\right)$

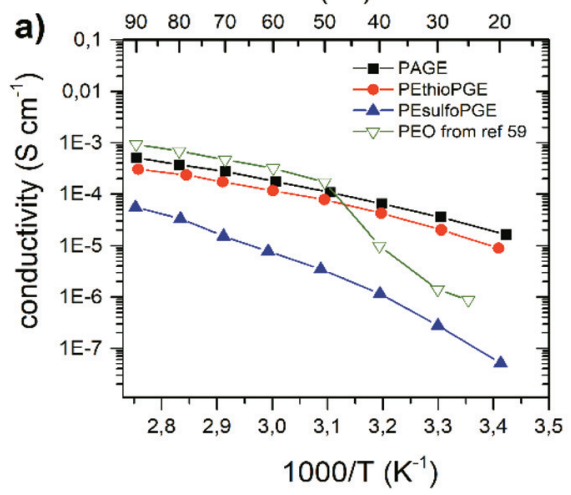

$\mathrm{T}\left({ }^{\circ} \mathrm{C}\right)$

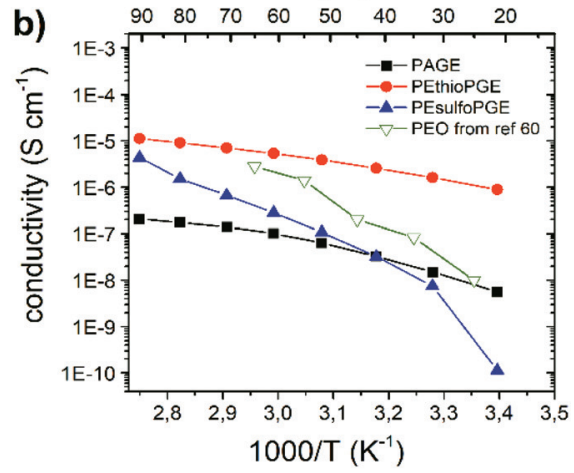

Fig. 3 Temperature-dependent conductivity for (a) LiTFSI and (b) LiCl polymer complexes. The available data for PEO-LiTFSI from ref. 59 and PEO$\mathrm{LiCl}$ from ref. 60 are also reported in (a) and (b), respectively, for comparison.

circuit shown in the inset in Fig. S14. $\dagger$ The performance of each polymer complex was tested by measuring the resistance as a function of temperature in the range $90-0{ }^{\circ} \mathrm{C}$. For the PEsulfoPGE-chloride complex, appreciable conductivity could be measured only down to $20-30^{\circ} \mathrm{C}$. The dependence of conductivity on temperature is summarized in Fig. 3 and 4. We found that the conductivity $\sigma(T) v s$. temperature plot can be well described using the Vogel-Tammann-Fulcher (VTF) equation (eqn (2)) as usually reported in the literature for polymeric solid electrolytes: ${ }^{43}$

$$
\sigma_{(T)}=\frac{\sigma_{0}}{\sqrt{T}} e^{-B / k_{\mathrm{B}}\left(T-T_{0}\right)}
$$

where $\sigma_{0}$ is a pre-exponential parameter related to the charge carrier density, $B$ is the pseudo-activation energy for ion conduction or segmental motion, $k_{\mathrm{B}}$ is the Boltzmann constant and $T_{0}$ is the VTF temperature, chosen to be $50 \mathrm{~K}$ below the $T_{\mathrm{g}}$ of the material. ${ }^{16}$ The variation of $\sigma_{0}$ with $T^{-1 / 2}$ is considered negligible compared to the exponential factor. ${ }^{43}$ It is important to note that the VTF behaviour is typical of systems where ion- pairing plays a minor role, whereas a $T$-dependent scaling is expected. $^{56}$

VTF plots for the TFSI and chloride complexes are reported in the ESI (Fig. S15 and S16†). As expected, the conductivity of all studied complexes shows a linear increase in the $\ln (\sigma) v s$. $\left(T-T_{0}\right)^{-1}$ plots with increasing temperature (moving from right to left). In the case of polymer-LiTFSI complexes, the highest conductivity values are found for PAGE $\left(5.1 \times 10^{-4} \mathrm{~S} \mathrm{~cm}^{-1}\right.$ at $\left.90{ }^{\circ} \mathrm{C}\right)$, closely followed by PEthioPGE $\left(3.0 \times 10^{-4} \mathrm{~S} \mathrm{~cm}^{-1}\right)$. PEsulfoPGE complexes show a significantly lower conductivity $\left(5.5 \times 10^{-5} \mathrm{~S} \mathrm{~cm}^{-1}\right)$. The conductivity value found for the PAGE-LiTFSI complex confirms the value reported previously by Barteau et al. for a similar polymer electrolyte but with a higher molecular weight. ${ }^{28}$ Interestingly, the thioether polymer exhibits comparable values of ionic conductivity. This may be explained by the good complexation of the sulfur atom and the Li-ions as commonly reported for ion-conducting glasses. ${ }^{27,57}$ Due to the amorphous nature of our polymers, the sudden conductivity drop observed below $50{ }^{\circ} \mathrm{C}$ for the PEO-LiTFSI complex due to the crystallization of PEO is not observed (Fig. 3). In the case of PEsulfoPGE, the lower conductivity
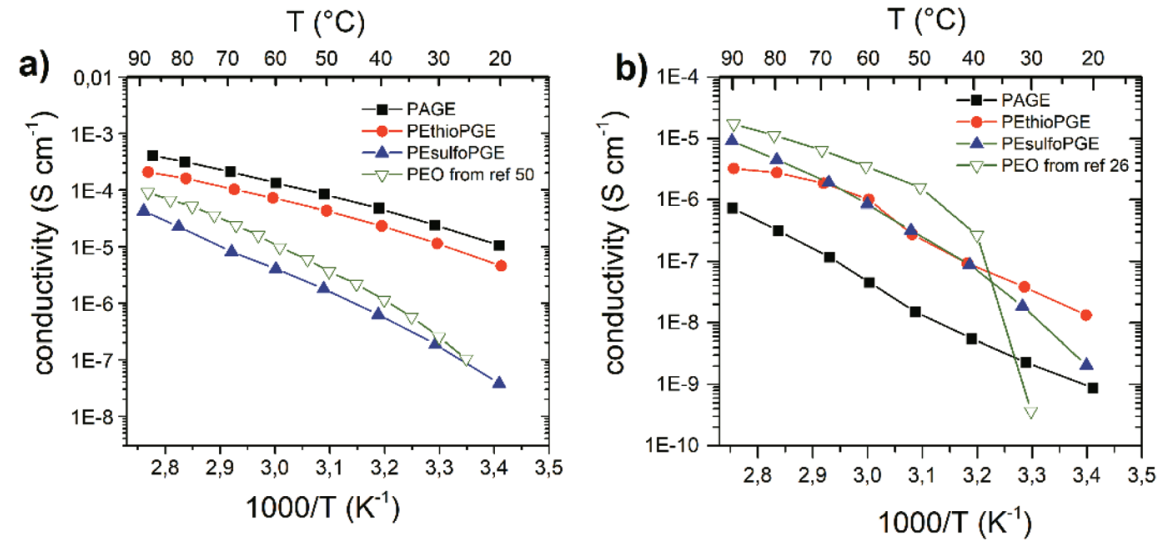

Fig. 4 Temperature-dependent conductivity of (a) $\mathrm{Mg}(\mathrm{TFSI})_{2}$ and (b) $\mathrm{MgCl}_{2}$ polymer complexes. The available data for $\mathrm{PEO} 9-\mathrm{Mg}(\mathrm{TFSI})_{2}$ from ref. 50 and $\mathrm{PEO}_{16}-\mathrm{MgCl}_{2}$ from ref. 26 are also reported in (a) and (b), respectively, for comparison. 
Table 1 Glass transition temperatures and calculated VTF pseudoenergy of activation $B$ for lithium and magnesium polymer electrolytes

\begin{tabular}{llllll}
\hline Polymer & Salt & {$[\mathrm{EO}] /[\mathrm{M}]$} & $r=[\mathrm{M}] /[\mathrm{O}]$ & $T_{\mathrm{g}}\left({ }^{\circ} \mathrm{C}\right)$ & $B(\mathrm{eV})$ \\
\hline PAGE & LiTFSI & 16 & 0.06 & -54.2 & 0.100 \\
PEthioPGE & LiTFSI & 16 & 0.06 & -64.5 & 0.120 \\
PEsulfoPGE & LiTFSI & 16 & 0.03 & -17.7 & 0.118 \\
PAGE & $\mathrm{LiCl}$ & 16 & 0.06 & -76.1 & 0.144 \\
PEthioPGE & $\mathrm{LiCl}$ & 16 & 0.06 & -73.8 & 0.098 \\
PEsulfoPGE & $\mathrm{LiCl}$ & 16 & 0.03 & -36.5 & 0.189 \\
PAGE & $\mathrm{Mg}(\mathrm{TFSI})_{2}$ & 16 & 0.06 & -50.7 & 0.107 \\
PEthioPGE & $\mathrm{Mg}(\mathrm{TFSI})_{2}$ & 16 & 0.06 & -59.0 & 0.174 \\
PEsulfoPGE & $\mathrm{Mg}(\mathrm{TFSI})_{2}$ & 16 & 0.03 & -17.8 & 0.117 \\
PAGE & $\mathrm{MgCl}_{2}$ & 16 & 0.06 & -77.0 & 0.272 \\
PEthioPGE & $\mathrm{MgCl}_{2}$ & 16 & 0.06 & -75.8 & 0.238 \\
PEsulfoPGE & $\mathrm{MgCl}_{2}$ & 16 & 0.03 & -9.7 & 0.126
\end{tabular}

could be ascribed to the lower Li/O ratio considering the sulfone oxygen, which leads also to a higher degree of coordination resulting in lower segmental mobility (higher $T_{\mathrm{g}}$ ).

Interestingly, the trend in the ionic conductivities of the $\mathrm{LiCl}$ complexes is different from that of LiTFSI: PEthioPGE > PEsulfoPGE $>$ PEO > PAGE. The best performance of PEthioPGE-LiCl is also combined with the lowest pseudo-activation energy (Table 1). However, the overall conductivities of the LiCl complexes remain one order of magnitude lower than those of the LiTFSI ones, in agreement with the lower solubility of the salt in the polymeric matrixes as observed experimentally by FTIR and DSC. The poor fit of the VTF behaviour for PAGE confirms that almost no interaction between the polymer and salt occurs. The differences in the trends between the conductivities of the LiTFSI and LiCl complexes may also reflect the differences in the interactions of the two anions with the host polymers. ${ }^{30,56,58}$ The strong dipole interaction of the sulfone group plays a major role in the conductivity of PEsulfoPGE, outperforming even PAGE which has a lower $T_{\mathrm{g}}$ of about $40^{\circ} \mathrm{C}$.

Recently, high $\mathrm{Mg}^{2+}$-ion conductivity and high $\mathrm{Mg}$ cycling efficiency have been achieved using $\mathrm{MgCl}_{2}$ salts in dialkyl sulfone electrolytes, motivating our endeavours to investigate $\mathrm{Mg}^{2+}$-ion conductivity in the synthesized sulfone containing solid polymer electrolytes. ${ }^{39,41}$ In Fig. 4 we report the transport properties of the $\mathrm{Mg}(\mathrm{TFSI})_{2}$ and $\mathrm{MgCl}_{2}$ complexes. For the TFSI complexes, the same trend observed for $\mathrm{Li}$ is found. Interestingly, the conductivity values are comparable to those of the LiTFSI complexes and, except for the more rigid PEsulfoPGE, they are all higher than the corresponding PEO complex with a higher salt concentration (see Fig. 4). The highest conductivity is found for the PAGE complex $\left(4.1 \times 10^{-4}\right.$ $\mathrm{S} \mathrm{cm}^{-1}$ at $\left.90{ }^{\circ} \mathrm{C}\right)$, followed by PEthioPGE $\left(2.1 \times 10^{-4} \mathrm{~S} \mathrm{~cm}^{-1}\right)$. For the $\mathrm{MgCl}_{2}$ complexes, a behaviour different from that of the $\mathrm{LiCl}$ case is observed. The conductivity scales as PEsulfoPGE > PEthioPGE > PAGE. The inversion between PEsulfoPGE and PEthioPGE can be attributed to the stronger interaction between the sulfone oxygen atoms and the magnesium cations, needed here to dissociate the less soluble $\mathrm{MgCl}_{2}$ salt. In fact, the $T_{\mathrm{g}}$ of the PEsulfoPGE- $\mathrm{MgCl}_{2}$ complex is the highest measured for all the electrolytes, even higher than the same polymer with the $\mathrm{Mg}(\mathrm{TFSI})_{2}$ counter ion (Table 1).

The VTF plot also shows that PEthioPGE- $\mathrm{MgCl}_{2}$ deviates from linearity, suggesting the low solubility of the salt inside this polymer, in agreement with the FTIR results (ESI Fig. S16 $)$. In general, all $\mathrm{MgCl}_{2}$ complexes have conductivities comparable to the corresponding $\mathrm{LiCl}$ complexes, although a steeper decrease at lower temperatures is observed due to the reduced solubility of the $\mathrm{Mg}$ salt. Although PEO performs better above $65{ }^{\circ} \mathrm{C}$, all synthesized polymers show higher conductivity below $50{ }^{\circ} \mathrm{C}$, as they do not exhibit crystallization behaviour typical of PEO. Moreover, although in the case of both PEthioPGE and PEsulfoPGE the ratio between the ions and the total functional groups is less than that in the case of PAGE, their conductivities with both lithium and magnesium chlorides are higher than that of the unsaturated polyether. This could also be attributed to the contribution from the anion as reported for other PEO complexes..$^{20,26,61,62}$ In order to evaluate the impact of the anion mobility on the overall conductivity, transference number measurements and battery tests will be performed and published in a separate study.

The impact of the host-polymer polarity is crucial and previous work based on simulations demonstrated that a balance between ion solvation and chain interaction exists. ${ }^{29,30}$ In our case, we proved experimentally that an increase in the dipole strength of the polymer backbone indeed promotes the solubilisation and dissociation of salts such as $\mathrm{LiCl}$ and $\mathrm{MgCl}_{2}$ but it also negatively affects the conductivity of TFSI-salts. The latter could be interpreted as an effect of the reduced mobility of the polymer due to strong interchain dipolar interaction which in turn affects the ion mobility through the electrolyte.

\section{Conclusions}

In this work, we demonstrated a practical and efficient way to synthesize poly(allyl glycidyl ether)-based polymer electrolytes with different types of functional short side chains, creating a new library of potential ion-conducting polymers. Poly(2(ethylthio) propyl glycidyl ether (PEthioPGE) and poly(2-(ethyl sulfone) propyl glycidyl ether (PEsulfoPGE) were successfully synthesized starting from poly(allyl glycidyl ether) via a sequential "thiol-ene" click reaction and oxidation. Fully amorphous polymers with $T_{\mathrm{g}}$ well below room temperature and thermal stability up to $300{ }^{\circ} \mathrm{C}$ were obtained. The increase in the oxidation state of the sulfur atom and the overall polarity of the side chain resulted in reduced segmental mobility with $T_{\mathrm{g}}$ varying from $-78{ }^{\circ} \mathrm{C}$ for PAGE to $-37{ }^{\circ} \mathrm{C}$ for PEsulfoPGE. All three synthesized polymers showed promising ion-conducting properties when mixed with different lithium and magnesium salts. Generally, PAGE shows better ion transport when LiTFSI is used, while the polymers containing functional polar side chains exhibit better ionic conductivities than PAGE when LiCl is used. Interestingly, owing to the high polarity of the polymers and the presence of the functional side chains, very good ionic conductivities are also reported 
here for complexes made with $\mathrm{Mg}(\mathrm{TFSI})_{2}$ and $\mathrm{MgCl}_{2}$ salts. Conductivity values competitive with the analogous PEO systems were measured. In some cases such as when mixed with $\mathrm{Mg}$ (TFSI $)_{2}$, the reported ionic conductivities outperform that of the benchmark PEO polymer. Conductivities as high as $4.1 \times 10^{-4} \mathrm{~S} \mathrm{~cm}^{-1}$ at $90{ }^{\circ} \mathrm{C}$ were registered. These aspects, together with the intrinsic absence of crystallization for both the neat polymers and the related $\mathrm{Li}$ and $\mathrm{Mg}$ complexes, constitute a great advantage for the future development of new polymeric materials for low and room temperature battery applications. In particular, applications where higher safety standards are required would benefit from the absence of liquid electrolytes, without dramatically affecting the performances.

\section{Conflicts of interest}

There are no conflicts to declare.

\section{Acknowledgements}

This project was financed via the start-up budget made available by the Zernike Institute for Advanced Materials. The authors acknowledge the Group of Photophysics and OptoElectronics of the Zernike Institute of Advanced Materials of the University of Groningen for giving access to their glove box for the preparation of the electrolytes. Albert J. J. Woortman is acknowledged for GPC analysis and Jur van Dijken is acknowledged for TGA measurements.

\section{Notes and references}

1 P. Meshram, B. D. D. Pandey and Abhilash, Resour. Policy, 2019, 60, 9-22.

2 Z. P. Cano, D. Banham, S. Ye, A. Hintennach, J. Lu, M. Fowler and Z. Chen, Nat. Energy, 2018, 3, 279-289.

3 Z. Ma, D. R. MacFarlane and M. Kar, Batteries Supercaps, 2019, 2, 115-127.

4 J.-M. M. Tarascon and M. Armand, Nature, 2001, 414, 359367.

5 Y. Ding, Z. P. Cano, A. Yu, J. Lu and Z. Chen, Electrochem. Energy Rev., 2019, 2, 1-28.

6 R. Deivanayagam, B. J. Ingram and R. Shahbazian-Yassar, Energy Storage Mater., 2019, 21, 136-153.

7 R. Mohtadi and F. Mizuno, Beilstein J. Nanotechnol., 2014, 5, 1291-1311.

8 P. Vanysek and D. R. Lide, CRC Handbook of Chemistry and Physics, CRC Press, Boca Raton, Florida, 70th edn, 1989.

9 D. Aurbach, I. Weissman, Y. Gofer and E. Levi, Chem. Rec., 2003, 3, 61-73.

10 J. Song, E. Sahadeo, M. Noked and S. B. Lee, J. Phys. Chem. Lett., 2016, 7, 1736-1749.

11 J. Mindemark, M. J. Lacey, T. Bowden and D. Brandell, Prog. Polym. Sci., 2018, 81, 114-143.
12 Z. I. Takehara, J. Power Sources, 1997, 68, 82-86.

13 D. T. Hallinan and N. P. Balsara, Annu. Rev., 2013, 43, 503.

14 D. E. Fenton, J. M. Parker and P. V. Wright, Polymer, 1973, 14, 589 .

15 D. F. Shriver, B. L. Papke, M. A. Ratner, R. Dupon, T. Wong and M. Brodwin, Solid State Ionics, 1981, 5, 83-88.

16 M. A. Ratner and D. F. Shriver, Chem. Rev., 1988, 88, 109124.

17 A. Patrick, M. Glasse, R. Latham and R. Linford, Solid State Ionics, 1986, 18-19, 1063-1067.

18 J. M. Parker, P. V. Wright and C. C. Lee, Polymer, 1981, 22, 1305-1307.

19 M. Gauthier, D. Fauteux, G. Vassort, M. Duval, P. Ricoux, D. Muller, P. Rigaud, M. B. Armand, D. Deroo, A. Bélanger, M. Duval, P. Ricoux, J.-M. Chabagno, D. Muller, P. Rigaud, M. B. Armand and D. Deroo, J. Electrochem. Soc., 1985, 132, 1333-1340.

20 A. V. Chadwick, J. H. Strange and M. R. Worboys, Solid State Ionics, 1983, 9-10, 1155-1160.

21 K. Chen and D. F. Shriver, Chem. Mater., 1991, 3, 771-772.

22 V. Di Noto, S. Lavina, D. Longo and M. Vidali, Electrochim. Acta, 1998, 43, 1225-1237.

23 S.-K. Jeong, Y.-K. Jo and N.-J. Jo, Electrochim. Acta, 2006, 52, 1549-1555.

24 M. Jaipal Reddy and P. P. Chu, J. Power Sources, 2002, 109, 340-346.

25 J. Sharma and S. A. Hashmi, J. Solid State Electrochem., 2013, 17, 2283-2291.

26 L. L. Yang, A. R. McGhie and G. C. Farrington, J. Electrochem. Soc., 1986, 133, 1380.

27 J. M. Sarapas and G. N. Tew, Macromolecules, 2016, 49, 1154-1162.

28 K. P. Barteau, M. Wolffs, N. A. Lynd, G. H. Fredrickson, E. J. Kramer and C. J. Hawker, Macromolecules, 2013, 46, 8988-8994.

29 B. K. Wheatle, S. Mogurampelly, J. R. Keith, N. A. Lynd and V. Ganesan, ACS Macro Lett., 2017, 6, 1362-1367.

30 B. K. Wheatle, N. A. Lynd and V. Ganesan, ACS Macro Lett., 2018, 7, 1149-1154.

31 H. Every, F. Zhou, M. Forsyth and D. MacFarlane, Electrochim. Acta, 1998, 43, 1465-1469.

32 M. Forsyth, J. Sun, D. R. Macfarlane and A. J. Hill, J. Polym. Sci., Part B: Polym. Phys., 2000, 38, 341-350.

33 M. Forsyth, J. J. Sun and D. R. MacFarlane, Solid State Ionics, 1998, 112, 161-163.

34 A. Sato, T. Okumura, S. Nishimura, H. Yamamoto and N. Ueyama, J. Power Sources, 2005, 146, 423-426.

35 H. Shimomoto, T. Uegaito, S. Yabuki, S. Teratani, T. Itoh, E. Ihara, N. Hoshikawa, A. Koiwai and N. Hasegawa, Solid State Ionics, 2016, 292, 1-7.

36 M. A. Webb, Y. Jung, D. M. Pesko, B. M. Savoie, U. Yamamoto, G. W. Coates, N. P. Balsara, Z.-G. G. Wang and T. F. Miller III, ACS Cent. Sci., 2015, 1, 198-205.

37 P. Johansson, Polymer, 2001, 42, 4367-4373.

38 J. Alvarado, M. A. Schroeder, M. Zhang, O. Borodin, E. Gobrogge, M. Olguin, M. S. Ding, M. Gobet, 
S. Greenbaum, Y. S. Meng and K. Xu, Mater. Today, 2018, 21, 341-353.

39 L. C. Merrill and J. L. Schaefer, Chem. Mater., 2018, 30, 3971-3974.

40 L. C. Merrill and J. L. Schaefer, Front. Chem., 2019, 7, $1-10$.

41 S.-J. Kang, S.-C. Lim, H. Kim, J. W. Heo, S. Hwang, M. Jang, D. Yang, S.-T. Hong and H. Lee, Chem. Mater., 2017, 29, 3174-3180.

42 B. F. Lee, M. J. Kade, J. A. Chute, N. Gupta, L. M. Campos, G. H. Fredrickson, E. J. Kramer, N. A. Lynd and C. J. Hawker, J. Polym. Sci., Part A: Polym. Chem., 2011, 49, 4498-4504.

43 S. Lascaud, M. Perrier, A. Vallée, S. Besner, J. Prud'homme and M. Armand, Macromolecules, 1994, 27, 7469-7477.

44 G. Socrates, Infrared and Raman characteristic group frequencies: Tables an charts, John Wiley \& Sons, Ltd, 3rd edn, 2004.

45 M. A. G. Martins and C. A. C. Sequeira, J. Power Sources, 1990, 32, 107-124.

46 A. Vallée, S. Besner and J. Prud'Homme, Electrochim. Acta, 1992, 37, 1579-1583.

47 I. Rey, J. C. C. Lassègues, J. Grondin and L. Servant, Electrochim. Acta, 1998, 43, 1505-1510.

48 S. J. Wen, T. J. Richardson, D. I. Ghantous, K. A. Striebel, P. N. Ross and E. J. Cairns, J. Electroanal. Chem., 1996, 408, 113-118.

49 M. Herstedt, M. Smirnov, P. Johansson, M. Chami, J. Grondin, L. Servant and J. C. Lassègues, J. Raman Spectrosc., 2005, 36, 762-770.
50 A. Bakker, S. Gejji, J. Lindgren, K. Hermansson and M. M. Probst, Polymer, 1995, 36, 4371-4378.

51 M. Deepa, S. A. Agnihotry, D. Gupta and R. Chandra, Electrochim. Acta, 2004, 49, 373-383.

52 S. P. Gejji, C. H. Suresh, K. Babu and S. R. Gadre, J. Phys. Chem. A, 2002, 103, 7474-7480.

53 X. Bogle, R. Vazquez, S. Greenbaum, A. V. W. Cresce and K. Xu, J. Phys. Chem. Lett., 2013, 4, 1664-1668.

54 A. Nitzan and M. A. Ratner, J. Phys. Chem., 1994, 98, 17651775.

55 S. D. Druger, A. Nitzan and M. A. Ratner, J. Chem. Phys., 1983, 79, 3133-3142.

56 N. A. Stolwijk, M. Wiencierz, C. Heddier and J. Kösters, J. Phys. Chem. B, 2012, 116, 3065-3074.

57 J. H. Kennedy, Z. Zhang and H. Eckert, J. Non-Cryst. Solids, 1990, 123, 328-338.

58 D. B. Shah, K. R. Olson, A. Karny, S. J. Mecham, J. M. DeSimone and N. P. Balsara, J. Electrochem. Soc., 2017, 164, A3511-A3517.

59 M. Chintapalli, T. N. P. Le, N. R. Venkatesan, N. G. Mackay, A. A. Rojas, J. L. Thelen, X. C. Chen, D. Devaux and N. P. Balsara, Macromolecules, 2016, 49, 1770-1780.

60 X. Q. Yang, H. S. Lee, C. Xiang, J. McBreen, L. S. Choi and Y. Okamoto, in Proceedings of Lithium Polymer Batteries Symposium, ed. J. Broadhead and B. Scrosati, San Antonio, 1996, vol. 96, pp. 146-153.

61 J. E. Weston and B. C. H. Steele, Solid State Ionics, 1981, 2, 347-354.

62 P. Ravn Sørensen and T. Jacobsen, Electrochim. Acta, 1982, 27, 1671-1675. 